tant are allowed time off for personal therapy at their own expense.

\section{Psychotherapy training for nurses}

The Uffculme Clinic was chosen as the first centre to run a Joint Board of Clinical Nursing Studies' course on psychotherapy. The first group of six nurses has just completed the course with gratifying results. These nurses co-lead intensive and out-patients groups; they also receive training in other therapies. The nurses take part in a weekly group experience with a group analyst and attend a day release course for psychodynamic training. It is encouraging to see the high calibre of applicants for such courses and trainees have been notably enthusiastic about their psychotherapeutic role.

\section{The West Midlands Institute of Psychotherapy}

This charitable institution has just been established and is based at Uffculme. It was brought into being with assistance from the Regional Health Authority in order to fulfil a regional need to bring together mental health professionals, including doctors, psychologists, social workers and marriage guidance counsellors, who have a special interest in psychotherapy or counselling. The Institute has over a hundred members, and, apart from monthly meetings, plans are being laid to develop further training courses.

\section{The Regional Centre for Postgraduate Psychiatry}

This is based at Uffculme and run in close conjunction with the Board of Graduate Clinical Studies of the University of Birmingham. It is responsible for the organization and administration of the schemes for higher psychiatric training, including the sub-specialties. Apart from the schemes and courses already mentioned, it organizes regular courses in family therapy and a training course in child development and analysis in conjunction with the Tavistock Clinic. It acts as a focal centre for the distribution of information about forthcoming meetings and training courses of psychiatric interest.

\title{
Undergraduate Teaching in Psychiatry
}

\section{Greg WiLkInson, Joint Senior Registrar, King's College and Maudsley Hospitals}

A workshop on the teaching of psychiatry to undergraduate medical students was held at the Institute of Psychiatry on 6 May 1981. Dr S. Greer and Dr C. Bass organized the meeting on behalf of the Association of University Teachers of Psychiatry, and there were sessions on four topics during the day; recruitment to psychiatry; the measurement of students' attitudes towards psychiatry and the use of 'liaison' psychiatry as a teaching method; the use of videotapes in teaching medical students interviewing skills-a practical demonstration; and a panel discussion of the problems in teaching undergraduates psychiatry.

Professor Gerald Russell (Institute of Psychiatry) began by asking the question 'How can recruitment to psychiatry be improved?' Evidence from the UK and the US fails, in general, to support the notion that improvements in undergraduate psychiatric education lead to an increased recruitment of psychiatrists. Instead, recent opinion suggests that the number of entrants to psychiatry is determined by ideological changes in society and economic and financial considerations. DR PETER BROOK (Fulbourn Hospital). spoke about the role of the medical schools in influencing career choice. Some schools consistently produce more psychiatrists than do others. Between 1966 and 1975 almost 7 per cent of University College Hospital graduates went into psychiatry, whereas only about 2 per cent of the London Hospital students did so. Schools at the 'top' of the 'league' have a relatively higher ratio of teaching consultants; and on average their students have a week longer psychiatric clerkship than do those whose schools were in the 'relegation zone'. Charismatic teachers seem to attract students to a career in psychiatry. Although neither speaker was able to give a clear explanation for the apparent decline in recruitment, two intriguing suggestions were raised for discussion. If the financial hypothesis is correct, then doubling the salary for mental handicap posts should increase recruitment to that sub-specialty (DHSS please note). Also, the College might like to consider ways of comparing standards of undergraduate psychiatric education in medical schools, and then through the use of student 'case-registers' graduates might be followed up to shed light upon the determinants of career choice.

Next, Charlotte Feinmann (King's College Hospital) presented the results of a questionnaire study designed to assess the effects of an eight-week course of instruction to improve clinical students' general interviewing skills. The questionnaires self-rated the students' attitudes toward, and competence at, interviewing; but there was little change in either despite the instruction. This might have reflected an increased sense of self-criticism in the participants. An incidental finding was that most of the subjects were enthusiastic about teaching received on ward-rounds and in out-patients rather than in other settings. DRS GREER and WILkINSON (King's College Hospital) described the preliminary results of a longitudinal study of medical students' attitudes towards psychiatry. Most of the King's students, happily, end their clerkship with a more enlightened view about psychiatric practice than when they start, but a few develop negative ideas about psychiatry. This second session of the day was completed by DR C. BASs (King's College Hospital) who gave a persuasive account of the potential role 
for 'liaison' psychiatry in the undergraduate teaching of psychiatry. Intuitively, 'liaison' psychiatry might be more relevant to students' future needs since the majority will become general practitioners and medical specialists. However, the meeting noted that there are dangers in an uncritical acceptance of the 'liaison' model. Manpower is short, and 'ordinary' psychiatric patients' needs are great too.

The early afternoon session was the highlight of the day, for DR P. MAGUIRE (University of Manchester) gave a splendid and greatly appreciated practical demonstration of the use of videotape in teaching undergraduates interviewing skills. Four students interview the same patient consecutively, each for 10 minutes, then they meet with $\mathrm{Dr}$ Maguire or one of his colleagues to discuss two of the four videos for one hour. These 'feedback' sessions have been shown to be an effective method of teaching a range of interview skills, and they are popular both with students and with patients-who rarely complain about the process. Not al Manchester students can benefit from this approach yet, but Dr Maguire is training members of staff in the teaching techniques. Schools with less resources might have difficulty in setting up such a service, but simpler methods could be used for these purposes, for example audiotape might be used as an alternative medium. The two King's medical students who

\section{News Items}

\section{Review Themes in Psychiatry}

Drs R. P. Snaith and S. Baugh of Leeds University Hospital have compiled a booklet entitled Review Themes in Psychiatry. This booklet contains lists of leading and review articles from five journals for the years 1971 to 1980 and grouped under subject headings in psychiatry. It is hoped it will be of use to all psychiatrists, especially those in training.

Review Themes in Psychiatry is available, free of charge, from Dr J. Attley, Astra Pharmaceuticals Ltd., St Peter's House, 2 Bricket Road, St Albans, Herts AL1 3JW.

\section{Journal of the Hong Kong Psychiatric Association}

Thirteen years after its foundation, the Hong Kong Psychiatric Association has started its own journal, Journal of the Hong Kong Psychiatric Association. At present it is to be published annually, but this will gradually be increased to more frequent appearances. Contributions of original papers and articles in the field of psychiatry and related disciplines are welcome.

Anyone interested in receiving the Journal should write to the Journal Committee, Hong Kong Psychiatric Associa- spoke at the meeting were impressed by the foregoing but they conveyed some trenchant criticism from the 'grassroots'. In their view, while psychiatrists seem to think that they are the only doctors who know about psychiatry, it is also the case that physicians and surgeons often pay only lipservice to psychological aspects of patient care.

The workshop concluded with a panel discussion of the day's events. Professor Cawley (King's College Hospital) summed-up for the panel by stressing the need that there was for medical schools to re-examine and restate the vocational and educational objectives of undergraduate training in psychiatry. We are likely to hear more about Dr Maguire's videotape teaching methods and Dr Bass's 'liaison' psychiatry teaching model; however, in these matters enthusiasm has to be checked by critical scrutiny. Finally, the main factors acting against an enlightened acceptance of psychiatry in the medical schools seem to be bad medicine, the half-baked sociology of the anti-psychiatrists, and bad psychiatry.

Other participants were $D_{R} R$. HrGGs, an academic general practitioner from King's College Hospital, $D_{R}$ G. LoYD, a consultant psychiatrist at Edinburgh Royal Infirmary (he chaired one of the morning sessions), and DR K. Petringale, senior lecturer in medicine, King's College Hospital. tion, c/o Rm. 801, Kelly Commercial Centre, 570-572 Nathan Road, Kowloon, Hong Kong.

\section{Historic Psychiatry Films}

The Audio-Visual Sub-Committee of the College is collaborating with the Mental Health Film Council and the National Film Archives in the presentation of mental health films of historical interest at the National Film Theatre in 1983. It is possible that old films illustrating treatment, care and aspects of hospital life exist, especially in mental illness and mental handicap hospitals and in research departments. These may be on $16 \mathrm{~mm}$., standard $8 \mathrm{~mm}$. or $9.5 \mathrm{~mm}$. film, and although they may have been taken originally to record methods of treatment or social events, they often contain other valuable comments on the period. This compilation by the National Film Archives could therefore be a valuable psychiatric retrospective and I would be grateful if I could be notified of the existence of such material. If used, they would of course be copied and the originals returned.

T. L. Prukington Honorary Secretary, Audio-Visual Sub-Committee 